\title{
Efeito da Adição de Feno de Catingueira (Caesalpinea bracteosa) na Ração sobre o Balanço de Energia e de Nitrogênio em Ovinos Morada Nova ${ }^{1}$
}

\section{Severino Gonzaga Neto ${ }^{2}$, Ângela Maria Vieira Batista ${ }^{3}$, Francisco Fernando Ramos de Carvalho ${ }^{3}$, Carlo Aldrovandi Torreão Marques ${ }^{4}$, Gladston Rafael Arruda Santos ${ }^{4}$}

\begin{abstract}
RESUMO - Objetivando avaliar o efeito da adição de feno de catingueira (FC) sobre os balanços de nitrogênio e de energia em ovinos Morada Nova, foram utilizados 15 animais machos, castrados, durante 22 dias. O delineamento estatístico foi inteiramente casualizado, com três tratamentos e cinco repetições. Os tratamentos consistiram da inclusão de 0,50 e $100 \%$ de FC à ração, na base da matéria seca. Os níveis de inclusão do FC às dietas não influenciaram nenhum dos parâmetros de balanço de nitrogênio. A perda média total de nitrogênio foi de $75,60 \%$ do ingerido e através da urina, de $61,31 \%$. Não se observou efeito dos níveis de inclusão de FC sobre os parâmetros de balanço de energia, exceto para a energia bruta perdida pelas fezes, que diminuiu linearmente, à medida que se aumentou a participação do FC às dietas. A perda média total de energia foi de 58,40\% da ingerida. Os resultados permitem indicar o feno de catingueira como fonte estratégica de alimento para os animais do semi-árido nordestino, sobretudo no período seco.
\end{abstract}

Palavras-chave: forrageira nativa, pequeno ruminante, tanino, semi-árido

\section{Effect of Catingueira Hay (Caesalpinea Bracteosa) Adition on Apparent Nitrogen and Energy Balance by Morada Nova Sheep}

\begin{abstract}
The objective of this study was to determine the effect of "catingueira" hay $(\mathrm{CH})$ addition on nutritional balance by sheep. Fifteen "Morada Nova" males castrated sheep were used in a complete randomized design with three treatments $(0$, 50 and $100 \% \mathrm{CH}$ addition) and five replications. The inclusion of $\mathrm{CH}$ did not influence the apparent nitrogen balance. The energy retained as percentage of the ingested energy was not affected by treatment, however, the energy retained as percentage of the digested energy declined linearly in function of the $\mathrm{CH}$ inclusion level. Considering the nutrititonal demands of the experimental animals, it was concluded that the average intake observed at the intermediary levels of $\mathrm{CH}$, showed that the "catingueira" have a reasonable nutritive value, being a strategic forage plant to the herd in the dry season in the semi-arid region.
\end{abstract}

Key Words: native forage, tanino, semi-arid, small ruminant

\section{Introdução}

Convencionalmente, em todas as regiões do Brasil, busca-se solucionar os déficits nutricionais, principalmente protéicos e energéticos, por meio de suplementos comerciais, na maioria dos casos, com satisfatórias respostas na produção, embora inviáveis sob o aspecto econômico. No centro-sul do Brasil, por exemplo, a solução para contornar o problema da estacionalidade na produção de forragem, tem sido o uso de concentrados, graças à proximidade aos centros produtores de grãos e ao menor preço pago pelo produto.
Em regiões mais afastadas desses centros, como o nordeste brasileiro, essa alternativa sido economicamente inviável para a produção pecuária, levando os produtores à dificuldade em manter os rebanhos durante a estiagem. Segundo Azevedo (1993), a carência protéica enfrentada no nordeste brasileiro pode ser suprida de forma econômica com o uso de leguminosas forrageiras, destacando-se as leguminosas nativas.

Segundo Degen et al. (1997), a necessidade de suplementação protéica de forma econômica e sustentável tem levado ao uso da folhagem de espécies arbóreas e arbustivas nas regiões áridas e semi-

\footnotetext{
${ }^{1}$ Parte da Dissertação do primeiro autor.

2 Pós-Graduando em Produção Animal UNESP-Jaboticabal. Via de Acesso Prof. Paulo D. Castellane, km 5 CEP: 14870-000. E.mail: gonzaga@fcav.unesp.br

3 Professor do DZ/UFRPE - Rua Dom Manuel de Medeiros S/N Dois Irmãos Recife-PE CEP: 52710-900. E.mail: baid@uol.com.br, ramosff@elogica.com.br

${ }^{4}$ Aluno do curso de Graduação em Zootecnia/UFRPE, bolsista PIBIC-CNPq/UFRPE.
} 
áridas de todo o mundo, sobretudo por árvores e arbustos permanecerem verdes durante o período seco.

Entre as diversas espécies nativas da caatinga, a catingueira, aliada a outros recursos naturais, apresenta-se como boa alternativa alimentar para os rebanhos desse ecossistema, pois mantém-se com bom teor de proteína bruta (em torno de 14\%), durante boa parte do ano, principalmente, por se tratar de uma espécie que se adapta muito bem à maioria dos solos e climas, além se ser bastante tolerante à seca (Barros et al., 1997). No entanto, informações acerca do valor nutritivo, dos dados de produção da catingueira e das quantidades máximas que devem ser oferecidas aos animais são praticamente inexistentes na literatura.

Este trabalho foi desenvolvido com o objetivo de avaliar o efeito da adição de feno de catingueira na ração sobre os balanços de energia e nitrogênio, em ovinos da raça Morada Nova.

\section{Material e Métodos}

O experimento foi conduzido no galpão de digestibilidade da sede da Empresa Pernambucana de Pesquisa Agropecuária-IPA, localizada na cidade de Recife, PE.

Foram utilizados 15 ovinos da raça Morada Nova, provenientes da Estação Experimental de Sertânea da Empresa Pernambucana de Pesquisa Agropecuária-IPA. Os animais, machos, castrados e vermifugados, foram pesados após 12 horas de jejum, no início e final do experimento, apresentando peso vivo médio inicial de $24,52 \mathrm{~kg}$ e peso vivo médio final de $24,86 \mathrm{~kg}$.

Os animais foram sorteados para os tratamentos e alojados por 22 dias em gaiolas de estudos metabólicos, equipadas com cochos, bebedouros e receptores de fezes e de urina. Os 15 dias iniciais destinaram-se à adaptação dos animais às novas condições de ambiente, manejo e alimentação e à excreção total do resíduo da alimentação anterior. Diariamente, durante sete dias, foram coletadas as fezes e urina e amostras do material ofertado e das sobras de cada animal, individualmente.

$\mathrm{Na}$ fase de adaptação, o feno de catingueira (FC) foi fornecido gradativamente em substituição ao feno de capim-de-planta (Brachiaria purpurascen) (FCP), utilizado como controle. As rações experimentais continham três níveis de FC $(0,50$ e 100\%), e o feno de capim-de-planta, utilizado como controle neste experimento, apresentou 5,8\% de PB (Tabela 1); por isto, adicionou-se $0,5 \%$ de uréia em relação ao total de FCP nas dietas com 0 e $50 \%$ do FC, que passaram a ter percentuais de 7,38 e $8,78 \%$ de $\mathrm{PB}$, respectivamente (Tabela 2 ).

Os animais receberam água e sal mineral à vontade, durante todo o período experimental.

No segundo dia do período de adaptação, iniciouse o ajuste da oferta, de modo a proporcionar, inicialmente, $30 \%$ de sobras e, no final, $20 \%$ para todos os animais.

Diariamente, as rações experimentais foram pesadas com base no consumo do dia anterior e acrescidas de $20 \%$, sendo fornecidas em duas porções diárias, às 8 e 15 h. Na ocasião, foram feitas as pesagens e anotações das quantidades de sobras, fezes e urina, tomando-se amostras correspondentes a $10 \%$ do total diário, para posterior análise da composição química, segundo metodologia de Silva (1990). Foi também determinado no FC o percentual de taninos condensados pelo método Folin-Denis, descrito por Magalhães et al. (1997).

O FC foi preparado na Estação Experimental de Sertânea, pertencente à Empresa Pernambucana de Pesquisa Agropecuária-IPA, e foi confeccionado com material na fase de frutificação, sendo composto por folhas e galhos finos.

O delineamento experimental utilizado foi o inteiramente casualizado com três tratamentos $(0,50 \mathrm{e}$ $100 \%$ de FC) e cinco repetições por tratamento.

As análises estatísticas dos dados foram realizadas com o auxílio do Programa SANEST - Sistema de Análises Estatística (Zonta e Machado, 1991), e todos os dados foram submetidos à análise de regressão.

A determinação da composição química dos fenos (Tabela 1) foi realizada no Laboratório de Nutrição Animal do Departamento de Zootecnia da Universidade Federal Rural de Pernambuco.

\section{Resultados e Discussão}

Os teores de proteína bruta (PB), proteína digestível (PD), energia bruta (EB), energia digestível (ED) e energia metabolizável (EM) e a quantificação do tanino das dietas experimentais, com base na matéria seca, são apresentados na Tabela 2 .

O teor de proteína bruta (PB) do feno de catingueira verificado neste trabalho foi de $11,25 \%$. Este teor pode ser considerado baixo, quando compa- 
rado com com os valores obtidos por Braga (1960), Araújo Filho \& Silva (1994 e Araújo Filho et al. (1998), de 17,$06 ; 15,25$ e $14,4 \%$, respectivamente, para a mesma forrageira, porém semelhante aos valores de 11,70 e $11,81 \%$, encontrados por Vasconcelos (1997) e Lima (1996), respectivamente.

O estado fenológico de confecção do feno de catingueira neste estudo foi o de frutificação. Segundo Araújo Filho et al. (1998), o estrato lenhoso da caatinga sofre flutuações no valor nutritivo ao longo do ano. Dessa forma, o feno de catingueira na fenofase de vegetação plena, ou seja, após o início da brotação (estação chuvosa), pode apresentar teor de proteína bruta próximo a $17 \%$. Esse valor reduz para $15,60 \%$ no estádio de floração, depois para $14,40 \%$ no estádio de frutificação e finalmente para $11,20 \%$ no estádio de dormência. Este último é determinado no restolho lenhoso, ou seja, nas folhas que caem por ocasião da senescência.

$\mathrm{O}$ feno de capim-de-planta, utilizado como controle neste experimento, apresentou inicialmente 5,8\% de PB (Tabela 1). Segundo Carneiro \& Rodriguez (1996), níveis inferiores a 7,0\% de PB na dieta podem prejudicar a fermentação ruminal e provocar balanço negativo de nitrogênio. Por isso, adicionou-se $0,5 \%$ de uréia em relação ao total de FCP nas dietas com

Tabela 1 - Composição química dos fenos de catingueira (FC) e de capim-deplanta (FCP), na base da matéria seca

Table 1 - Chemical composition of the catingueira hay (Caesalpinea bracteosa) and of plantgrass hay (Brachiaria purpurascens), in dry matter basis

\begin{tabular}{|c|c|c|}
\hline $\begin{array}{l}\text { Parâmetros } \\
\text { Parameters }\end{array}$ & $\begin{array}{c}\mathrm{FC} \\
\text { Catingueira hay }\end{array}$ & $\begin{array}{c}\text { FCP } \\
\text { Brachiaria hay }\end{array}$ \\
\hline Proteína bruta $(\%)$ & 11,25 & 5,80 \\
\hline Crude protein (\%) & & \\
\hline Proteína digestível (\%) & 7,39 & 3,71 \\
\hline $\begin{array}{l}\text { Energia bruta (Kcal/kg MS }) \\
\text { Gross energy }(\mathrm{kcal} / \mathrm{kg} \mathrm{DM})\end{array}$ & $4.507,91$ & $4.047,20$ \\
\hline $\begin{array}{l}\text { Energia digestível (Kcal/kg MS) } \\
\text { Digestible energy }(\mathrm{kcal} / \mathrm{kg} \text { DM) }\end{array}$ & $2.052,45$ & $1.767,41$ \\
\hline $\begin{array}{l}\text { Tanino }(\%) \\
\text { Tanin }(\%)\end{array}$ & 6,30 & - \\
\hline
\end{tabular}

Tabela 2 - Composição química das dietas experimentais, na base da matéria seca

Table 2 - Chemical composition of experimental diets, in dry matter basis

\begin{tabular}{|c|c|c|c|}
\hline \multirow[t]{2}{*}{$\begin{array}{l}\text { Parâmetros } \\
\text { Parameters }\end{array}$} & \multicolumn{3}{|c|}{$\begin{array}{l}\text { Níveis de feno de catingueira } \\
\text { Catingueira hay level }\end{array}$} \\
\hline & $0 \%$ & $50 \%$ & $100 \%$ \\
\hline Proteína bruta (\%) & 7,38 & 8,78 & 11,25 \\
\hline Crude protein (\%) & & & \\
\hline Proteína digestível (\%) & 4,72 & 5,57 & 7,39 \\
\hline Digestible protein $(\%)$ & & & \\
\hline Energia bruta (kcal/kg MS) & $4.047,20$ & $4.230,31$ & $4.507,91$ \\
\hline Gross energy (kca/kg DM) & & & \\
\hline Energia digestível (kcal/kg MS) & $1.767,41$ & $1.904,91$ & $2.052,45$ \\
\hline Digestible energy $(\mathrm{kcal} / \mathrm{kg} D M)$ & & & \\
\hline $\begin{array}{l}\text { Energia metabolizável }(\mathrm{kcal} / \mathrm{kg} \mathrm{MS})^{*} \\
\text { Metabolizable energy }(\mathrm{kcal} / \mathrm{kg} \mathrm{DM})^{*}\end{array}$ & $1.449,28$ & $1.562,03$ & $1.683,01$ \\
\hline Tanino $(\%)$ & - & 3,15 & 6,30 \\
\hline $\operatorname{Tanin}(\%)$ & 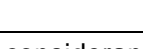 & $\pi$ & 0 \\
\hline
\end{tabular}

R. Bras. Zootec., v.33, n.5, p.1325-1331, 2004 
0 e $50 \%$ do FC, que passaram a ficar com percentuais de 7,38 e 8,78\% de PB, respectivamente (Tabela 2). Essa iniciativa parece ter proporcionado duas situações diferentes: por um lado, observou-se melhor ajuste na oferta de PB entre as dietas. Por outro, o fornecimento de nitrogênio prontamente disponível (uréia), nas dietas com 0 e $50 \%$ de FC, parece ter proporcionado equilíbrio no aproveitamento do alimento pelos microrganismos ruminais nas diferentes dietas experimentais, o que pode ter beneficiado aquelas com menor inclusão de FC.

Com relação à concentração de tanino, o valor observado foi de $6,30 \%$. Este valor pode ser considerado baixo, se comparado aos 18,59 e $9,10 \%$ de tanino total, determinados na mesma espécie por Vasconcelos (1997) e Araújo Filho et al. (1998), respectivamente, embora esteja acima faixa de concentração $(4,0 \%)$, que não provoca alterações no rúmen, em ovinos. Segundo Reed (1995), altas concentrações de tanino em folhas de leguminosas diminuem acentuadamente o consumo, por alterarem a palatabilidade, além de afetarem a digestibilidade da fibra pelas ligações formadas com enzimas bacterianas e/ou formação de complexos indigestíveis com carboidratos da parede celular. Narjisse et al. (1995) afirmam que níveis de até 6\% de tanino não afetam a digestibilidade em ovinos, mas interferem no consumo, que, segundo Barros et al. (1997), é um dos fatores que afeta diretamente a digestibilidade. Acima desta concentração, Narjisse et al. (1995) verificaram que a capacidade de fermentação do fluido ruminal foi marcadamente deprimida, principalmente em ovinos, espécie bastante sensível a esta substância.

Para fins de compreensão, estimou-se o consumo de proteína digestível (CPD), expresso em $\mathrm{g} / \mathrm{kg}^{0,75}$ / dia. De acordo com o NRC (1985), as exigências mínimas de mantença de peso vivo para ovinos são de $2,47 \mathrm{~g} / \mathrm{kg}^{0,75} / \mathrm{dia}$ de PD. Os animais que receberam dietas com 0,50 e $100 \%$ de FC consumiram, em média, 3,39; 3,66 e 3,99 g de $\mathrm{PD} / \mathrm{kg}^{0,75} / \mathrm{dia}$, respectivamente, correspondendo, portanto, a 37,25; 48, $18 \mathrm{e}$ $61,54 \%$ acima das exigências de mantença.

Os parâmetros de balanço aparente de nitrogênio (BN) dos animais utilizados neste experimento, conforme dados da Tabela 3 , não foram influenciados $(\mathrm{P}>0,05)$ pelos níveis de inclusão do FC nas dietas. Observa-se que, em valores absolutos, a quantidade de $\mathrm{N}$ retido nos níveis 50 e $100 \%$ de FC foram superiores. No entanto, esta resposta não foi signifi- cativa $(\mathrm{P}>0,05)$, provavelmente em virtude do alto coeficiente de variação $(56,28 \%)$.

A quantidade de $\mathrm{N}$ digerido também não sofreu influência $(\mathrm{P}>0,05)$ dos níveis de inclusão do $\mathrm{FC}$, o que pode estar relacionado aos semelhantes valores de perda de $\mathrm{N}$ através das fezes, em relação ao $\mathrm{N}$ ingerido nos níveis $0=37,73 \%, 50=40,57 \%$ e $100 \%$ de $\mathrm{FC}=35,64 \%$. Embora não se tenha observado efeito $(\mathrm{P}>0,05)$ entre os tratamentos, o aumento do teor de proteína da dieta tendeu à melhoria do balanço de nitrogênio dos animais.

$\mathrm{O} \mathrm{N}$ retido como porcentagem do digerido e do ingerido também não sofreu influência $(\mathrm{P}>0,05)$ do tratamento, embora, tenha sido observada, em valores absolutos, tendência de aumento de $\mathrm{N}$ retido com a maior participação do FC, indicando menor perda do $\mathrm{N}$ absorvido, através da urina nos níveis com maior participação de $\mathrm{FC}$, fato que provavelmente está associado aos maiores teores de PB, quando comparados aos níveis mais baixos de FC.

A perda média total de nitrogênio foi de $75,60 \%$ do ingerido, enquanto, através da urina, se perdeu $61,31 \%$ do digerido ou absorvido.

Os resultados do balanço aparente de energia dos animais usados neste experimento são apresentados na Tabela 4. Na realidade, representam retenção aparente, pois foram medidas apenas as perdas de energia pelas fezes e urina.

Estimou-se também o consumo de energia digestível (CED), expresso em $\mathrm{kcal} / \mathrm{kg}^{0,75} / \mathrm{dia}$, verificando-se valores médios de 110,34; 113,02 e 96,08, nos níveis de 0,50 e $100 \%$ de FC, respectivamente. A exigência média de ED para mantença de ovinos com aproximadamente $25 \mathrm{~kg}$ de peso vivo, segundo NRC (1985), é de $199 \mathrm{kcal} / \mathrm{kg}^{0,75} / \mathrm{dia}$. Portanto, com base nessa informação, verifica-se um déficit de ED na ordem de 44,55; 43,21 e 51,72\%, respectivamente.

Não houve efeito $(\mathrm{P}>0,05)$ dos níveis de FC sobre a retenção aparente de energia (Tabela 4). Com base no CED e nas exigências mínimas de mantença para ovinos com aproximadamente $25 \mathrm{~kg}$ de peso vivo, discutidos anteriormente neste trabalho, verificou-se um déficit de ED para os três níveis de inclusão do FC estudados. Entretanto, não houve balanço negativo de energia, provavelmente, porque, neste trabalho, analisou-se apenas o balanço aparente de energia. Dessa forma, não foram computadas as perdas dos gases nem as perdas provenientes da queda de pêlos. Se essas medidas fossem computadas, certamente, o balanço de energia seria

R. Bras. Zootec., v.33, n.5, p.1325-1331, 2004 
negativo, uma vez que as quantidades de energia ingerida não atenderam às exigências dos animais em estudo.

A energia perdida pelas fezes diminuiu linearmente $(\mathrm{P}<0,05)$ com a inclusão do FC. Para os demais parâmetros, não houve efeito $(\mathrm{P}>0,05)$ do $\mathrm{FC}$, com máximos valores absolutos de energia ingerida, digerida e retida para níveis intermediários de inclusão do FC.

A energia retida como porcentagem da ingerida não sofreu influência $(\mathrm{P}>0,05)$ do tratamento, ao passo que, para a energia retida como percentagem da digerida, observou-se declínio linear $(\mathrm{P}<0,05)$, com a maior participação do FC. A perda média total de energia foi de $58,40 \%$ do ingerido.

Os dados de excreção média diária de urina (Tabela 5) foram submetidos à análise de regressão para se observarem possíveis relações do total de urina excretada por dia com as perdas de nitrogênio e energia. Entretanto, não se verificou efeito $(\mathrm{P}>0,05)$ dos níveis de inclusão do FC sobre esta variável.
Comparando-se os valores de $\mathrm{N}$ perdido na urina (Tabela 3) com os valores de urina excretados diariamente (Tabela 5), para os diferentes níveis de FC, constata-se, proporcionalmente, que os animais no nível $0 \%$ perderam mais nitrogênio, embora, excretassem menos urina/dia. O contrário ocorreu com os animais no nível $100 \%$ de FC que, mesmo excretando mais urina/dia, perderam menos nitrogênio. Embora, não se tenha medido a ingestão diária de água, observou-se que os animais que consumiram dietas contendo FC ingeriram mais água e, conseqüentemente, produziram mais urina. Este fato pode estar relacionado à presença de tanino neste material.

\section{Conclusões}

Os níveis de inclusão de feno de catingueira às dietas experimentais não afetaram os balanços de nitrogênio e de energia, o que permite considerá-lo como um alimento estratégico para o período seco.

Tabela 3 - Efeito da adição de feno de catingueira na ração sobre o balanço aparente de nitrogênio em ovinos Morada Nova

Table 3 - Efect of catingueira hay adition on apparent nitrogen balance by Morada Nova sheep

\begin{tabular}{|c|c|c|c|c|c|}
\hline \multirow[t]{2}{*}{$\begin{array}{l}\text { Parâmetros } \\
\text { Parameters }\end{array}$} & \multicolumn{3}{|c|}{$\begin{array}{l}\text { Níveis de feno de catingueira } \\
\text { Catingueira hay level }\end{array}$} & \multirow[t]{2}{*}{$\begin{array}{l}\text { Média } \\
\text { Mean }\end{array}$} & \multirow[t]{2}{*}{$\begin{array}{l}\mathrm{CV}^{1} \\
(\%)\end{array}$} \\
\hline & $0 \%$ & $50 \%$ & $100 \%$ & & \\
\hline $\begin{array}{l}\text { g/dia } \\
\text { g/day }\end{array}$ & & & & & \\
\hline $\begin{array}{l}\text { N ingerido }(\mathrm{g} / \text { dia }) \\
N \text { ingested }(g / \text { day })\end{array}$ & 8,53 & 9,49 & 9,95 & 9,17 & 13,56 \\
\hline $\begin{array}{l}\mathrm{N} \text { fecal (g/dia) } \\
\text { Fecal } N(\text { g/day })\end{array}$ & 3,22 & 3,85 & 3,55 & 3,54 & 15,81 \\
\hline $\begin{array}{l}\text { N urinário }(\mathrm{g} / \text { dia }) \\
\text { Urinary } N(\text { g/day })\end{array}$ & 3,75 & 3,35 & 3,53 & 3,54 & 21,18 \\
\hline $\begin{array}{l}\mathrm{N} \text { digerido }(\mathrm{g} / \text { dia }) \\
N \text { digested }(\mathrm{g} / \text { day })\end{array}$ & 5,31 & 5,64 & 6,40 & 5,78 & 16,83 \\
\hline $\begin{array}{l}\text { Balanço de } \mathrm{N}(\mathrm{g} / \mathrm{dia}) \\
N \text { balance }(\mathrm{g} / \text { day }) \\
\text { Balanço de } \mathrm{N} \\
N \text { balance }\end{array}$ & 1,57 & 2,28 & 2,86 & 2,24 & 56,28 \\
\hline $\begin{array}{l}\% \text { do ingerido } \\
\% \text { of ingested }\end{array}$ & 17,87 & 23,95 & 27,37 & $\hat{Y}=23,06$ & 10,22 \\
\hline $\begin{array}{l}\% \text { do digerido } \\
\% \text { of digested } \\
\text { N digerido } \\
\text { Digested } N\end{array}$ & 28,44 & 40,32 & 41,82 & $\hat{Y}=36,86$ & 44,20 \\
\hline $\begin{array}{l}\% \text { do ingerido } \\
\% \text { of ingested }\end{array}$ & 62,10 & 59,57 & 64,02 & $\hat{Y}=61,90$ & 6,89 \\
\hline
\end{tabular}

$1 \mathrm{CV}=$ Coeficiente de variação (Coefficient of variation). 
Tabela 4 - Efeito da adição de feno de catingueira na ração sobre o balanço aparente de energia em ovinos Morada Nova e respectivas equações de regressão em função dos níveis de inclusão (Î) de feno de catingueira nas dietas experimentais e respectivos coeficientes de determinação $\left(R^{2}\right)$ e de variação $(C V)$

Table 4 - Efect of catingueira hay $(\mathrm{CH})$ adition on apparent energy balance by Morada Nova sheep and respective regresion equation in function of the Catingueira hay inclusion level (I) and coefficient of determination $\left(R^{2}\right)$ and variation $(C V)$

\begin{tabular}{|c|c|c|c|c|c|c|}
\hline \multirow{2}{*}{$\begin{array}{l}\text { Parâmetros } \\
\text { Parameters }\end{array}$} & \multicolumn{3}{|c|}{$\begin{array}{c}\text { Níveis de feno de catingueira } \\
\text { Catingueira hay level }\end{array}$} & \multirow[t]{2}{*}{$\begin{array}{l}\mathrm{R}^{2} \\
(\%)\end{array}$} & \multirow[t]{2}{*}{$\begin{array}{l}\mathrm{CV} \\
(\%)\end{array}$} & \\
\hline & $0 \%$ & $50 \%$ & $100 \%$ & & & \\
\hline \multicolumn{7}{|l|}{$\begin{array}{l}\mathrm{kcal} / \mathrm{dia} \\
\mathrm{kcal} / \text { day }\end{array}$} \\
\hline $\begin{array}{l}\mathrm{EB}^{1} \text { ingerido } \\
G E^{2} \text { ingested }\end{array}$ & $2.756,4$ & $2.809,8$ & $2.334,9$ & $\hat{Y}=2.633,7$ & & 15,4 \\
\hline $\begin{array}{l}\text { EB fecal } \\
G E \text { in feces }\end{array}$ & $1.539,7$ & $1.548,4$ & $1.264,6$ & $\hat{Y}=1.588,461-2,75092 \mathrm{I}^{*}$ & 72,6 & 13,7 \\
\hline $\begin{array}{l}\text { EB urinária } \\
\text { Urinary } G E\end{array}$ & 75,2 & 97,6 & 90,5 & $\hat{Y}=87,8$ & & 24,7 \\
\hline $\begin{array}{l}\text { EB digerida } \\
\text { GE digeted }\end{array}$ & $1.216,7$ & $1.261,4$ & $1.070,3$ & $\hat{Y}=1.182,8$ & & 20,2 \\
\hline $\begin{array}{l}\text { Balanço (g/dia) } \\
\text { Balance (g/day) } \\
\text { Balanço } \\
\text { Balance }\end{array}$ & $1.141,5$ & $1.163,8$ & 979,7 & $\hat{Y}=1.095,0$ & & 21,0 \\
\hline $\begin{array}{l}\% \text { do ingerido } \\
\% \text { of ingested }\end{array}$ & 41,00 & 41,50 & 41,57 & $\hat{Y}=41,4$ & & 8,9 \\
\hline $\begin{array}{l}\% \text { do digerido } \\
\% \text { of digested } \\
\text { EB digerida } \\
\text { GE digested }\end{array}$ & 93,91 & 92,18 & 91,17 & $\hat{Y}=93,792-0,02744 \mathrm{I}^{*}$ & 97,7 & 2,0 \\
\hline $\begin{array}{l}\% \text { da ingerida } \\
\% \text { of ingested }\end{array}$ & 43,67 & 45,03 & 45,53 & $\hat{Y}=44,7$ & & 8,0 \\
\hline
\end{tabular}

Tabela 5 - Excreção média de urina ( $\mathrm{mL} / \mathrm{dia})$, em função dos níveis de inclusão (î) do feno de catingueira $(F C)$ nas dietas experimentais e respectivos coeficientes de variação (CV)

Table 5 - Mean urinary excretion ( $\mathrm{mL} /$ day), in function of catingueira hay inclution (I) and the respective coefficient of variation (CV)

\begin{tabular}{lccccc}
\hline & \multicolumn{2}{c}{$\begin{array}{c}\text { Níveis de feno de catingueira } \\
\text { Catingueira hay level }\end{array}$} & & $\begin{array}{c}\text { Média } \\
\text { Mean }\end{array}$ & CV (\%) \\
\cline { 2 - 4 } & $0 \%$ & $50 \%$ & $100 \%$ & & \\
\hline $\begin{array}{l}\text { Produção de urina } \\
\text { Urine production }\end{array}$ & 563,17 & 905,20 & 935,17 & & 801,18 \\
\hline
\end{tabular}

\section{Literatura Citada}

AGRICULTURAL RESEARCH COUNCIL - ARC. The Nutrient requirement of ruminant livestock. Old Working: The Greham Press, 1980. 347p.

ARAÚJO FILHO, J.A.; CARVALHO, F.C.; GADELHA, J.A. et al. Fenologia e valor nutritivo de espécies lenhosas cauducifólias da caatinga. In: REUNIÃO ANUAL DA SOCIEDADE BRASILEIRA DE ZOOTECNIA, 35., 1998, Botucatu. Anais... Botucatu: Sociedade Brasileira de Zootecnia, 1998. p.360-362.

ARAÚJO FILHO, J.A.; SILVA, N.L. Alternativas para o aumento da produção de forragem na caatinga. In: SIMPÓSIO NORDESTINO DE ALIMENTAÇÃO DE RUMINAN- 
TES, 5., 1994, Salvador. Anais... Salvador: Sociedade Nordestina de Produção Animal, 1994. p.121-133.

AZEVEDO, A.R. Sistemas de utilização das leguminosas leucena e cunhã. Areia: Universidade Federal da Paraíba, 1993. Palestra proferida na UFPB, Areia, out. 1993.

BARROS, N.N; SOUSA, F.B.; ARRUDA, F.A.V. Utilização de forrageiras e resíduos agroindustriais por caprinos e ovinos. Sobral: EMBRAPA - CNPC, 1997. 28p. (Documentos, 26)

BRAGA, R. Plantas do Nordeste, especialmente do Ceará. 2.ed. Fortaleza: Imprensa Oficial, 1960. 540p.

CARNEIRO, J.C.; RODRIGUEZ, N.M. Digestibilidade aparente e balanço de nitrogênio da palha de soja em ovinos e caprinos. In: REUNIÃO ANUAL DA SOCIEDADE BRASILEIRA DE ZOOTECNIA, 33., 1996, Fortaleza. Anais... Fortaleza: Sociedade Brasileira de Zootecnia, 1996. p.54-56.

DEGEN, A.A.; BLANKE, A.; BECKER, K. et al. The nutritive value of Acacia saligna and Acacia salicina for goats and sheeps. Animal Science, v.64, n.2, p.253-259, 1997.

LIMA, J.L.S. Plantas forrageiras da caatinga - usos e potencialidades. Petrolina: EMBRAPA - CPATSA/PNE/ RBG-KEW, 1996. 44p.

MAGALHÃES, P.C.; RODRIGUES, W.A.; DURÃES, F.O.M. Tanino no grão de sorgo - bases fisiológicas e métodos de determinação. Sete Lagoas: EMBRAPA - CNPMS, 1997. 26p. (Circular Técnica, 27)
NARJISSE, H.; ELHONSALI, M.A.; OLSEN, J.D. Effects of oak (Quercus ilex) tannins on digestion and nitrogen balance in sheep and goats. Small Ruminants Research, v.18, n.2, p.201-206, 1995.

NATIONAL RESEARCH COUNCIL - NRC. Nutrient requirements of sheep. Washington, D.C.: National Academy of Sciences, 1985. 99p.

REED, J.D. Nutritional toxicology of tannins and related polyphenols in forage legumes. Journal of Animal Science, v.73, n.4, p.1516-1528, 1995.

SILVA, D.J. Análise de alimentos: métodos químicos e biológicos. 2.ed. Viçosa, MG: Universidade Federal de Viçosa, 1990. 166p.

VASCONCELOS, V.R. Caracterização química e degradação de forrageiras do semi-árido brasileiro no rúmen de caprinos. Jaboticabal: Universidade Estadual Paulista, 1997. 132p. Tese (Doutorado em Zootecnia) - Universidade Estadual Paulista, 1997.

ZONTA, E.P.; MACHADO, A.A. SANEST - Sistema de Análises Estatísticas. Campinas: IAC, 1991. 48p.

Recebido em: 22/11/01

Aceito em: 24/11/03 